\title{
Hyposensibilisierung in Andalusien
}

\begin{abstract}
n Südspanien sind Olivenpollen das klinisch wichtigste Aeroallergen. Über 80\% der Allergiker dieser Region sind gegen Olea europaea sensibilisiert, in Andalusien kann die Konzentration an Ölbaumpollen in der Luft Spitzenwerte von 7.000 Pollen $/ \mathrm{m}^{3}$ erreichen. In einer randomisierten kontrollierten Studie konnten Allergologen aus Jaén jetzt die Sicherheit und Wirksamkeit einer 1-jährigen spezifischen Hyposensibilisierung mit einem standardisierten Olivenextrakt belegen. Bei 23 Patienten mit Rhinitis oder Asthma aufgrund einer Monosensibilisierung gegen Olea europaea führte die Immuntherapie im Vergleich zu Plazebo zu einer Reduktion von Medikamentenbedarf und Sympto-
\end{abstract}

\section{Ratteninduziertes Asthma}

at n 1, das Hauptallergen der Ratte, spielt in der Allergieentwicklung offensichtlich ein wichtigere Rolle als bisher angenommen - zumindest in den Innenbezirken amerikanischer Großstädte. In Baltimore im USBundesstaat Maryland konnte das Allergen in 33\% der Wohnungen von Kindern mit Asthma nachgewiesen werden. $21 \%$ der Kinder waren gegen das Rat-

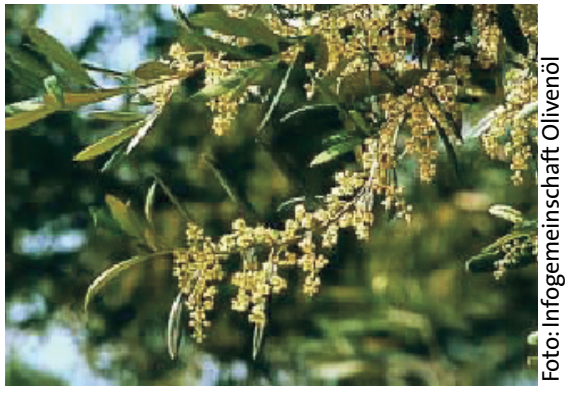

matik. Der verwendete Allergenextrakt von ALK-Abelló war standardisiert bezüglich der Gesamtallergenaktivität und des Gehalts an Majorallergen Ole e 1. $c l$

González P et al. J Invest Allergol Clin Im-

munol 2002; 12: 263-71

\section{Prophylaxe mit Pilzen}

A ährend man bei den IgE-abhängigen Atemwegsallergien mit der spezifischen Immuntherapie bereits direkt kausal in das immunologische Geschehen eingreifen kann, verliefen entsprechende Versuche bei den IgE-vermittelten Nahrungsmittelallergien wenig ermutigend. Taiwanesische Forscher verfolgten daher die Idee der Immunprophylaxe von Nahrungsmittelallergien - und können im Tierversuch bereits über Erfolge berichten. Als Immunmodulator diente ein Protein aus Flammulina velutipes, einem essbaren asiatischen Pilz. Prophylaktisch oral gegeben, schützte es Mäuse vor einer experimentell erzeugten Nahrungsmittelallergie: Im Vergleich zu Kontrollmäusen zeigten die „immunisierten“ Mäuse eine weniger ausgeprägte IgE-Reaktion und eine eher TH1-dominierte Zytokinantwort. Da das Protein von den Mäusen gut vertragen wurde, möchte man nun bald auch am Menschen testen.

tenallergen sensibilisiert, die Sensibilisierung korrelierte jedoch nicht mit dem Nachweis von Rattenallergenen in den Wohnungen. Diese dürfte in der Regel außerhalb der Wohnung auf Spielplätzen oder in Schulen stattgefunden haben.

$b k$

Perry T et al. J Allergy Clin Immunol

2003; 112: 346-52

\section{Allergieschutz durch maternale Zytokine}

D ass Brustfütterung Kinder vor Allergien schützt ist bekannt, nicht aber warum. Nachdem erstmals in den 90er Jahren in der Muttermilch Zytokine nachgewiesen wurden, machten sich nun australische Forscher auf die Suche nach möglichen Zusammenhängen. In einer prospektiven Kohortenstudie kor-

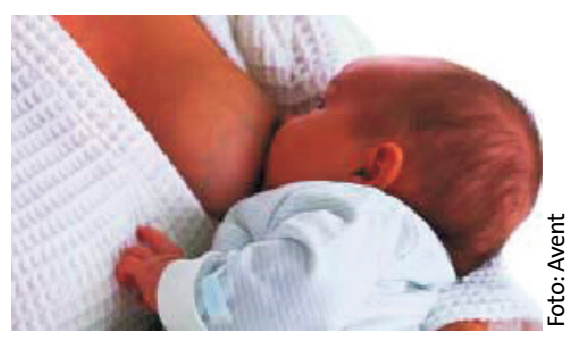

relierten sie das Symptom „wheezing“ bei Säuglingen mit dem Zytokinmuster der jeweiligen Muttermilch. Diese zeigte zwar eine sehr heterogene Zusammensetzung, in der Multivarianzanalyse ergab sich aber ein stark reduziertes „wheezing "-Risiko bei höheren Werten von TGF- $\beta 1$ (OR 0,22). TGF- $\beta 1$ ist eines der häufigsten Zytokine in der Muttermilch. Es wird für eine beschleunigte Lungenreifung und für eine Synthesesteigerung von IgA verantwortlich gemacht, wodurch die kindliche Schleimhaut vor Infektionen geschützt wird. $b k$

Oddy WH et al. J Allergy Clin Immunol 2003; 112: 723-8
Hsieh KY et al. Clin Exp Allergy 2003; 33: 1595-1602

\section{Olympische Allergene}

riechenland erwartet zu den Olympischen Spielen 2004 mehr als 16.000 Athleten. Rund 20\% davon, so Schätzungen, leiden unter allergischen Atemwegserkrankungen und sind für ihre Höchstleis-

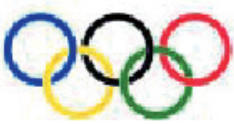
tungen auf möglichst exakte Vorhersagen der Aeroallergenbelastung angewiesen. Während für eine der Wettkampfstätten, Thessaloniki, bereits seit 15 Jahren Pollenflugaufzeichnungen existieren, wurden in Heraklion auf Kreta und in Athen, dem Hauptaustragungsort, im Vorfeld der Spiele eigens Burkard-Fallen installiert und ein Messsystem etabliert. Während der Wettkämpfe im August und September ist vor allem mit dem Flug von Gänsefußund Beifußpollen sowie von Alternaria und Cladosporium zu rechnen.

es

Gioulekas D et al. Allergy 2003; 58: 933-8 